\title{
Eosinophilic colitis
}

\author{
Isabel José Dionísio de Sousa, Nuno Bonito, Ana Pais, Helena Gervásio
}

Department of Medical

Oncology, Portuguese Institute of Oncology Francisco Gentil,

Coimbra, Portugal

\section{Correspondence to}

Dr Isabel José Dionísio de

Sousa,

isajose8@gmail.com

Accepted 21 February 2016

\section{SUMMARY}

A 57-year-old man, diagnosed with colon cancer stage

III in July/2010, underwent surgery and received adjuvant chemotherapy with FOLFOX 4 (5-fluorouracil; calcium folinate and oxaliplatin), which ended in March/ 2011 after 12-cycles. It was then decided to maintain periodical surveillance. About 1 year later, the patient developed several episodes of diarrhoea, mainly during the night, and presented persistent peripheral eosinophilia in the blood count (range 585-1300 eosinophils/ $\mu \mathrm{L}$ ). Colonoscopy was performed, with the histological result showing eosinophilic infiltration of the colon, compatible with eosinophilic colitis. The patient was treated with a short course of budesonide, achieving resolution of symptoms, and has remained asymptomatic.

\section{BACKGROUND}

Eosinophilic colitis (EC) is a rare entity with unclear mechanism of action and few therapeutic approaches, based on small case series/reports. As with any rare disease, all additional information collected from new cases is important to establish a better approach/treatment. We present a case of EC in the context of oncological disease. This article will be of interest to professionals in the medical community, especially those in the oncology field.

\section{CASE PRESENTATION}

A 57-year-old man with an Eastern Cooperative Oncology Group performance status (ECOG PS) 0 and a medical history of absent kidney, seborrhoeic keratosis, severe osteoporosis and non-insulindependent diabetes, at the end of 2009 , developed rectal bleeding with progressive worsening associated with tenesmus. A colonoscopy performed in July/2010 showed a haemorrhagic and ulcerating lesion $30 \mathrm{~cm}$ from the anal margin, occupying 25\% of the lumen. The histological examination revealed a well-differentiated adenocarcinoma. A thoracoabdominal CT scan did not show any signs of metastasis. The patient was, therefore, submitted to a sigmoidectomy in May/2010, with histology confirming the presence of a well-differentiated adenocarcinoma with subserosal invasion, safe margins and metastases in 5 of the 17 dissected lymph nodes-pT3N2a. The patient began chemotherapy with FOLFOX 4, ending in March/2011 after 12-cycles. It was then decided to maintain periodical surveillance. In the beginning of 2012, the patient presented several episodes of daily diarrhoea, mainly during the night, and blood count showing persistent peripheral eosinophilia (range 585-1300 eosinophils/ $\mu \mathrm{L}$ ).

\section{INVESTIGATIONS}

Colonoscopy was performed with the histological result showing eosinophilic infiltration of the colon, compatible with EC (figure 1A-C).

In April 2012, the patient was diagnosed with myocardial infarction, after presenting acute chest pain and a simultaneous hypertensive crisis. In light of these new developments, the suspicion of a Churg-Strauss syndrome was raised, but considered unlikely after persistent negative autoantibody test results.

\section{TREATMENT}

The patient was treated with a short course of budesonide.

\section{OUTCOME AND FOLLOW-UP}

The patient experienced resolution of symptoms and has remained asymptomatic.

He was evaluated by haemato-oncology consultants, but no other abnormalities, namely in the peripheral smear, were found.

The patient maintains periodical evaluation by medical oncology and hemato-oncology consultants.

\section{DISCUSSION}

EC is an exceptionally rare entity and its mechanism of action is still unclear. Therapeutic approaches are scarce and based on small case series/reports. EC in adults seems to be a nonimmunoglobulin E (IgE)-associated disorder, apparently acting through a CD4Th2 lymphocytemediated mechanism. ${ }^{1} 2$ It is frequently independent of blood eosinophilia, thus distinguishing it from blood eosinophilic states. ${ }^{12}$ Colonic eosinophilia can also occur in helminthic infections, inflammatory bowel disease, autoimmune disease, coeliac disease, drug reactions and hypereosinophilic syndrome. ${ }^{1}$ Clinical features of EC depend on the location, extent and layer(s) of bowel involved. If the mucosa layer is affected, abdominal pain, nausea, vomiting, early satiety and diarrhoea are common symptoms. ${ }^{3}$ When involvement of the muscle layer occurs, wall thickening and impaired motility may lead to intestinal obstruction with nausea, vomiting and abdominal distention. Infiltration of subserosal may lead to isolated ascites or ascites in combination with the symptoms previously mentioned. ${ }^{3}$ Suspicion of EC should be raised if a patient presents with abdominal pain, nausea, vomiting, early satiety, diarrhoea, weight loss or ascites associated with peripheral eosinophilia (>500 eosinophils/ $\mu \mathrm{L}$ ), without a determined cause. Diagnosis is established if eosinophilic infiltration of the gastrointestinal tract and/or 

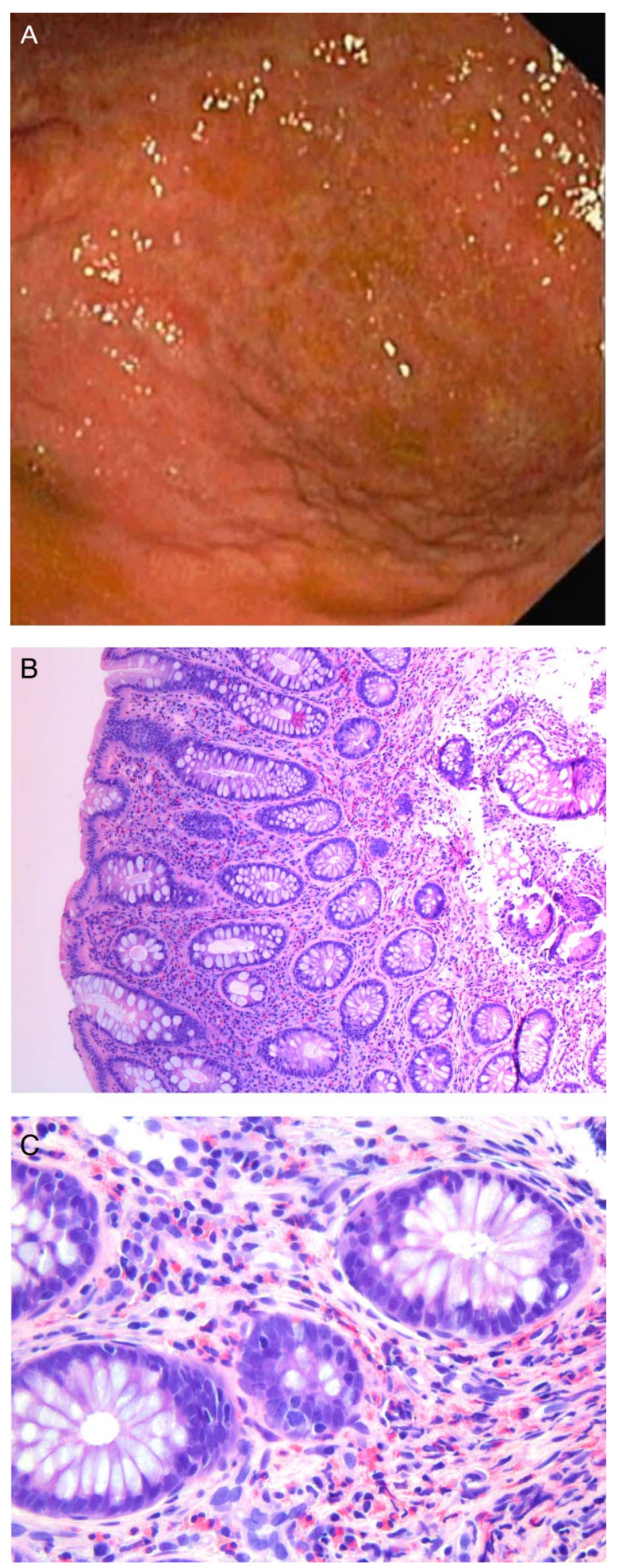

Figure 1 (A) Colonoscopic view showing mucosal congestion and nodular changes-biopsies were performed (acknowledgement goes to the Gastroenterology Department of the Portuguese Institute of Oncology, Coimbra). (B) Eosinophilic infiltration of the lamina propria of the colon (acknowledgement goes to the Pathology Department of the Portuguese Institute of Oncology, Coimbra). (C) Eosinophilic infiltration of the lamina propria of the colon (acknowledgement goes to the Pathology Department of the Portuguese Institute of Oncology, Coimbra). eosinophilic ascitic fluid is demonstrated. Few treatment options exist, and none with robust results. In infants' elimination diets, aiming to identify food sensitivities might be beneficial, but older individuals may require more aggressive management because IgE-associated triggers are rarely identified. Corticosteroids, namely oral prednisone, used in most studies, have shown improved clinical and pathological findings. In relapses, long-term, low-dose corticosteroids may be required. ${ }^{4}$ Budesonide has been reported to induce and maintain remission. Immunomodulatory agents (eg, azathioprine) can be used in severe, refractory or steroid-dependent EC. ${ }^{5}$ The role of montelukast, particularly in the steroid-sparing context, and antihistamines, is not established. Emerging therapies focusing on humanised monoclonal antibodies that target inflammatory mediators are being evaluated. The natural history of EC is not well defined but, in adults, tends to become chronic, with periods of exacerbation and remission.

\section{Learning points}

- Eosinophilic colitis (EC) is an exceptionally rare entity and its mechanism of action is still unclear.

- Suspicion of EC should be raised if a patient presents with abdominal pain, nausea, vomiting, early satiety, diarrhoea, weight loss or ascites associated with peripheral eosinophilia (>500 eosinophils/ $\mu \mathrm{L}$ ), without a determined cause.

- Few treatment options exist, and none with robust results.

Acknowledgements The authors thank the Gastroenterology and Pathology Departments of the Portuguese Institute of Oncology, Coimbra.

Competing interests None declared.

Patient consent Obtained.

Provenance and peer review Not commissioned; externally peer reviewed.

\section{REFERENCES}

1 Alfadda AA, Storr MA, Shaffer EA. Eosinophilic colitis: epidemiology, clinical features, and current management. Therap Adv Gastroenterol 2011;4:301-9.

2 Kweon MN, Yamamoto M, Kajiki M, et al. Systemically derived large intestinal $\mathrm{CD}^{+} \mathrm{Th} 2$ cells play a central role in STAT6-mediated allergic diarrhea. J Clin Invest 2000;106:199-206.

3 Talley NJ, Shorter RG, Phillips SF, et al. Eosinophilic gastroenteritis: a clinicopathological study of patients with disease of the mucosa, muscle layer, and subserosal tissues. Gut 1990;31:54-8.

4 Chen MJ, Cheng HC, Lin SC, et al. Eosinophilic gastroenteritis: clinical experience with 15 patients. World J Gastroenterol 2003;9:2813-16.

5 Rothenberg M. Eosinophilic gastrointestinal disorders (EGID). Molecular mechanisms in allergy and clinical immunology. J AllergyClin Immunol 2004;113:11-28. 
Copyright 2016 BMJ Publishing Group. All rights reserved. For permission to reuse any of this content visit http://group.bmj.com/group/rights-licensing/permissions.

BMJ Case Report Fellows may re-use this article for personal use and teaching without any further permission.

Become a Fellow of BMJ Case Reports today and you can:

- Submit as many cases as you like

- Enjoy fast sympathetic peer review and rapid publication of accepted articles

- Access all the published articles

- Re-use any of the published material for personal use and teaching without further permission

For information on Institutional Fellowships contact consortiasales@bmjgroup.com

Visit casereports.bmj.com for more articles like this and to become a Fellow 